\title{
The tropical circulation: Simple model versus general circulation model
}

\author{
By ANDREW W. ROBERTSON* and CLAUDE FRANKIGNOUL \\ Laboratoire d'Oceanographie Dynamique et de Climatologie, Université Pierre et Marie Curie, \\ 4 place Jussieu, 75230 Paris cedex 05, France
}

(Received 30 December 1988; revised 28 July 1989 )

SUMMARY

An attempt is made to simulate two general-circulation-model-produced February climatologies in the tropics (from the GISS and the LMD GCMs), using a linear steady-state multi-layer primitive equations model which is forced thermally. A hypothesis-testing strategy is used to quantify the simulations of the target climatologies taking into account the natural variability of the GCM fields. When the zonal-mean flow and the diabatic heating field are prescribed from the GCM, the linear model is found to be generally consistent with both GCMs at the $5 \%$ level of statistical significance. The linear model simulation of the GCM is most successful for the vertical velocity. The horizontal wind field is moderately well simulated at low and high levels, but poorly in the mid troposphere. More than $40 \%$ of the spatial variance at 850 and $950 \mathrm{mb}$ between $30^{\circ} \mathrm{S}$ and $15^{\circ} \mathrm{N}$ is explained in the LMD GCM climatology whereas the corresponding figure for the GISS climatology is $34 \%$ at $850 \mathrm{mb}$, falling off toward the surface. The linear model's skill at simulating the LMD climatology near the ground is little diminished when the forcing is restricted to the trade-cumulus layer only. However, midtropospheric heating is found to be important for the zonal component of the flow at low levels, especially close to the equator. Sensitivity, especially at upper levels, was found to the inclusion of the zonal component of the mean wind in the linearization, but little to the mean meridional circulation. Sensitivity to the linear model dissipation is also discussed.

\section{INTRODUCTION}

The distribution of tropical diabatic heating is fundamental to the large-scale atmospheric circulation in the tropics and in particular to the zonal overturning along the equator, known as the Walker circulation (Bjerknes 1969). Changes in diabatic heating play a major role in the El Niño-Southern Oscillation (ENSO) phenomenon which dominates the global climate variability on the interannual time scale, involving large changes in sea surface temperature (s.s.t.) over the equatorial Pacific, and zonal shifts in the tropical zone of intense convection and latent-heat release. Any attempt to model ENSO requires a coupled ocean-atmosphere model. Because of the long time scale and aperiodicity of ENSO, long simulations are needed to investigate the underlying dynamics and to make predictability studies. Thus although the ability to forecast the phenomenon accurately must eventually lie with coupled general circulation models (GCMs), simple models that represent the main features of the ocean-atmosphere system are very desirable. In fact, useful ENSO forecasts have been produced by a very simple coupled model (Zebiak and Cane 1987), whilst low-resolution atmospheric GCMs are only just beginning to have the finesse required (Latif et al. 1987).

In this study, we develop a simple thermally forced linear model of the tropical atmosphere which could eventually be coupled to an ocean model for ENSO studies. The model is linearized about a prescribed zonally symmetric state, as these models reproduce poorly the zonally symmetric component of the flow (Neelin 1988). Attention is given to quantifying how well the zonal asymmetries of the tropical climate can be simulated, in particular at low levels. Since model validation would be difficult with observations because of the problems of constructing the diabatic heating and the vertical * Present affiliation: Meteorologisches Institut der Universität München, Theresienstr. 37, 8000 München 2 ,
West Germany 
velocity from observed data, we use GCM-produced climatologies to test and tune the linear model. At the same time, such an approach enables investigation of the GCM climatologies themselves, using the linear model as a tool.

The net effect of tropical cloud clusters is to give rise to localized regions of intense mean latent heating which peak in the middle to upper troposphere (e.g. Hartmann et al. 1984). The location and variability of these regions of deep convection is believed to be strongly associated with the s.s.t. distribution. Oceanic time scales are long compared with the adjustment time of the tropical atmosphere, so that it is of primary relevance to investigate the response of the tropical atmosphere to a fixed heating distribution. In recent years there has been much theoretical work on simple models of the tropical response to diabatic heat sources, starting with the work of Matsuno (1966); e.g. Webster (1972), Gill (1980), Geisler (1981), Lim and Chang (1983). Most of these studies are based on the Matsuno-Gill model. This linear, dissipative shallow-water-equations model has been rather successful at reproducing the main features of the tropical response to a steady, equatorial heat source, particularly at low levels (to a first approximation, tropical latent heating excites the first baroclinic mode). This success of linear theory is due firstly to the very close linear thermodynamic balance between mean latent heating, and mean ascent (adiabatic cooling) above the planetary boundary layer in the tropics-which by continuity of mass, yields a good estimate of the low-level convergent wind. Secondly, linear theory holds reasonably well for the associated rotational component of the flow at low levels where vorticity advection by the ambient flow is weak. This tends to be less so at upper levels where the time-mean flow is strong (Sardeshmukh and Hoskins 1985), but dissipation can be included to parametrize somehow the effects of nonlinearities and transients (Simmons 1982, Nigam et al. 1986).

In order to take into account the vertical structure of both the forcing and the basic state, and to resolve the near-surface flow sufficiently well, we have developed a steadystate linear primitive-equations model with six layers in the vertical. Its relevance is evaluated by simulating the zonal asymmetries of the February-mean tropical climatologies of two GCMs which were kindly made available to us. The first model is the Goddard Institute for Space Studies (GISS) model 2, a low-resolution GCM (Hansen et al. 1983), and the second, the higher-resolution model of the Laboratoire de Meteorologie Dynamique (LMD) (Sadourny and Laval 1984). The linear model's basic states and heating fields are prescribed from the GCM in question and the predicted wind fields then compared with those of the GCM. Other forcing mechanisms, such as transient eddy forcing, orography and interactions with higher latitudes, are present in the GCMs but not in the linear model. Thus although it is hoped that thermal forcing in the tropics will dominate the tropical response, we expect to reproduce only part of the Walker circulation. It is therefore appropriate to make the model comparison in the space of the linear model response while keeping as an additional measure of the fit, the proportion of the GCM signal that projects in that space.

Even in the tropics, GCMs have, like the atmosphere itself, a considerable natural variability, so that the comparison with the linear model must be done statistically. In the present case, the GCM variability can be estimated since both climatologies are means over a 'sample' of five Februaries. The validity of the simple model simulation is decided by applying the statistical method developed in Hannoschöck and Frankignoul (1985), and testing if the linear model response and the GCM simulation are consistent. This technique provides a direct measure of the fit, and is particularly adapted to examining the sensitivity of the linear model to the various simplifying assumptions and parameters used. We shall consider, in particular, the roles of the basic state, the dissipation, and the vertical distribution of the forcing. 
We begin by discussing in section 2 our simple linear-dissipative model and its behaviour in idealized situations. Section 3 outlines the testing procedure used in the comparison between the GCM climatologies and the simple model. In sections 4 and 5 we briefly outline the GCMs and discuss in turn how well their climatologies are simulated by the linear model. A summary and conclusions follow in section 6 .

\section{THE LINEAR MODEL}

Our simple model is a global, steady-state, linear, dissipative, multi-layer primitiveequations model. The equations of motion are linearized about the full three-component zonally-averaged flow.

The steady-state hydrostatic primitive equations on the sphere are written:

$$
\begin{gathered}
\alpha_{\mathrm{r}} U+\bar{D} U+D \bar{U}-\frac{\mu}{\left(1-\mu^{2}\right)} \frac{\bar{U} V+U \bar{V}}{a}-2 \mu \Omega V+\frac{1}{a} \frac{\partial \phi}{\partial \lambda}=0 \\
\alpha_{\mathrm{r}} V+\bar{D} V+D \bar{V}+\frac{\mu}{\left(1-\mu^{2}\right)} \frac{2 \bar{U} U}{a}+2 \mu \Omega U+\frac{\left(1-\mu^{2}\right)}{a} \frac{\partial \phi}{\partial \mu}=0 \\
\alpha_{\mathrm{n}} T+\bar{D} T+D \bar{T}-(\kappa / p)(\bar{\omega} T+\omega \bar{T})=Q \\
\frac{1}{\left(1-\mu^{2}\right)} \frac{1}{a} \frac{\partial U}{\partial \lambda}+\frac{1}{a} \frac{\partial V}{\partial \mu}+\frac{\partial \omega}{\partial p}=0 \\
\partial \phi / \partial p=-R T / p
\end{gathered}
$$

where

$$
D=\left(\frac{U}{\left(1-\mu^{2}\right)} \frac{1}{a} \frac{\partial}{\partial \lambda}+\frac{V}{a} \frac{\partial}{\partial \mu}+\omega \frac{\partial}{\partial p}\right)
$$

is the advection operator, overbars denotes zonal averages and all the other variables describe deviations from zonal symmetry. Here $U=u \cos \theta$ and $V=v \cos \theta$ where $u$ and $v$ are the velocity components on a pressure surface in the longitudinal $(\lambda)$ and latitudinal $(\theta)$ directions respectively, and $\mu=\sin \theta$. The vertical coordinate is pressure $p$, $\omega=D p / D t, \phi$ is geopotential height, $T$ temperature and $Q$ the diabatic heating rate. Also, $a$ is the earth's radius, $\Omega$ its angular velocity, $R$ the universal gas constant, and $\kappa$, the ratio of $R$ to the specific heat at constant pressure.

The only damping mechanisms included are linear, with spatial variation in both the vertical and meridional directions. $\alpha_{\mathrm{r}}$ is the coefficient of Rayleigh friction and $\alpha_{n}$ that of Newtonian cooling. In the standard version of the model (i.e. unless stated otherwise), we employ the linear damping formulation used by Nigam et al. (1986), which comprises a boundary-layer drag parametrization with a damping time scale, $\alpha_{\mathrm{b}}^{-1}$, of 1 day at $1000 \mathrm{mb}$, decreasing linearly to zero at $800 \mathrm{mb}$, and an enhanced friction where the mean zonal wind $\bar{u}$ becomes small, to remove the critical-line singularity (i.e. $\bar{u}=0$ ), given in days by

$$
\alpha_{c}^{-1}=1 \cdot 5 \exp \{\bar{u} /(6 \cos \theta)\}^{2}
$$

where $\bar{u}$ is in $\mathrm{m} / \mathrm{s} . \alpha_{\mathrm{c}}$ reaches a maximum of $(1.5 \text { days })^{-1}$ at the critical line, and quickly becomes negligible for $\bar{u} / \cos \theta>6 \mathrm{~m} / \mathrm{s}$. The local value of $\alpha_{\mathrm{r}}$ in our model is set equal to the larger, locally, of $\alpha_{\mathrm{b}}$ and $\alpha_{\mathrm{c}}$. This yields a tropical band extending some 15-20 either side of the equator, of very high uniform dissipation (damping times of about 2 days). Damping times are uniformly about 1 day near the surface, whilst in the westerly 
belts at upper levels in middle latitudes they exceed 100 days. A linear cooling $\alpha_{\mathrm{n}}$, with a time scale of 5 days at $1000 \mathrm{mb}$ decreasing to 20 days at $200 \mathrm{mb}$ and constant above, is included, in an attempt to mimic transient eddy heat flux convergences at low levels (Kang and Held 1986), as well as radiational cooling. In the sensitivity experiments of sections 4 and 5, some of these damping parametrizations are modified.

The model is 'semi-spectral' with the variables Fourier analysed in the zonal direction but finite differenced in the meridional and vertical. We employ second-order finite differences in both directions which are staggered in the vertical for maximum accuracy and simplicity, so that the momentum and continuity equations are applied at the layer centres, whilst the thermodynamic equation is applied at layer interfaces.

After eliminating $T$, Eqs. (1)-(4) are Fourier analysed in the zonal direction. For each zonal wavenumber, the equations are finite differenced and the resulting block matrix system solved subject to the boundary conditions $\omega=0$ at 0 and $1000 \mathrm{mb}$, and $(U, V, \omega, \phi)=0$ at the poles, using the technique of Lindzen and Kuo (1969). The tropical response is found to be almost indistinguishable if the lateral boundary condition is replaced by $d / d \mu$ of $(U, V, \omega, \phi)=0$ at the poles. We use 8 (section 4$)$ or 10 (section 5) zonal wavenumbers, 21 latitudes pole-to-pole equispaced in sine(latitude) (giving 11 latitudes between $30^{\circ} \mathrm{N}$ and $30^{\circ} \mathrm{S}$ ), and 6 layers in the vertical. The upper 4 layers are each $200 \mathrm{mb}$ thick, bounded above by the $0 \mathrm{mb}$ and below by the $800 \mathrm{mb}$ surfaces. Underneath are two $100 \mathrm{mb}$-thick layers which can be approximately identified with the trade-cumulus boundary layer. This vertical configuration is chosen to retain simplicity, but captures reasonably the structure of the thermal forcing, and the low-level flow. However, inevitably some accuracy is sacrificed, and ideally one would have used the same vertical finite difference structure as in the GCMs to be considered. Note that as the diabatic heating is carried at layer interfaces and there is no surface heating, the average heating in the layer $1000-850 \mathrm{mb}$ must be prescribed at $900 \mathrm{mb}$, in order to conserve the vertically integrated heating.

As an example of the model response in an idealized situation, Fig. 1 shows the perturbation wind and geopotential height fields at $300 \mathrm{mb}$ when the model is forced by an isolated heating centred on the equator with a Gaussian spatial shape (Gaussian scale of $40^{\circ}$ longitude and $11.5^{\circ}$ latitude). The heating has a parabolic vertical structure with a maximum of $6 \mathrm{~K} / \mathrm{d}$ at $400 \mathrm{mb}$, and corresponds to a precipitation rate $1 \mathrm{~cm} / \mathrm{d}$ at the centre. Here a 5-day damping time scale is employed uniformly on $(U, V)$ and $T$.

With a motionless basic state, the response at $300 \mathrm{mb}$ (Fig. 1(b)) shows the characteristic linear picture with divergence predominantly along the equator above the heat source and two anticyclones straddling the equator to the west of the heating (Gill 1980; Geisler 1981). At $700 \mathrm{mb}$ (not shown) the reverse picture is found, with low-level convergence and cyclones lying below the upper anticyclones, so that the response is predominantly in the first baroclinic mode. Gill and others have interpreted the eastwest asymmetry in terms of a Rossby wave response to the west of the heating and a three-times-faster Kelvin wave to the east. This asymmetry is altered by the Doppler shifting effect of the mean wind, which mainly acts on the slower Rossby wave. The effect of linearizing about a uniform $10 \mathrm{~m} / \mathrm{s}$ easterly current (Fig. 1(a)) is to decrease the meridional scale by diminishing the Rossby wave response, while linearizing about a $10 \mathrm{~m} / \mathrm{s}$ westerly current (Fig. 1(c)) produces a stronger, nearer resonant Rossby wave response at the expense of the Kelvin wave, and thus a broader meridional scale. As long as the zonal-mean current remains uniform, no high latitude teleconnection response is produced, as barotropic modes are not excited by a purely internal heat source in the absence of mean wind shear and surface friction (Lim and Chang 1983).

The model behaviour in Fig. 1 is in agreement with that of existing models (e.g. 

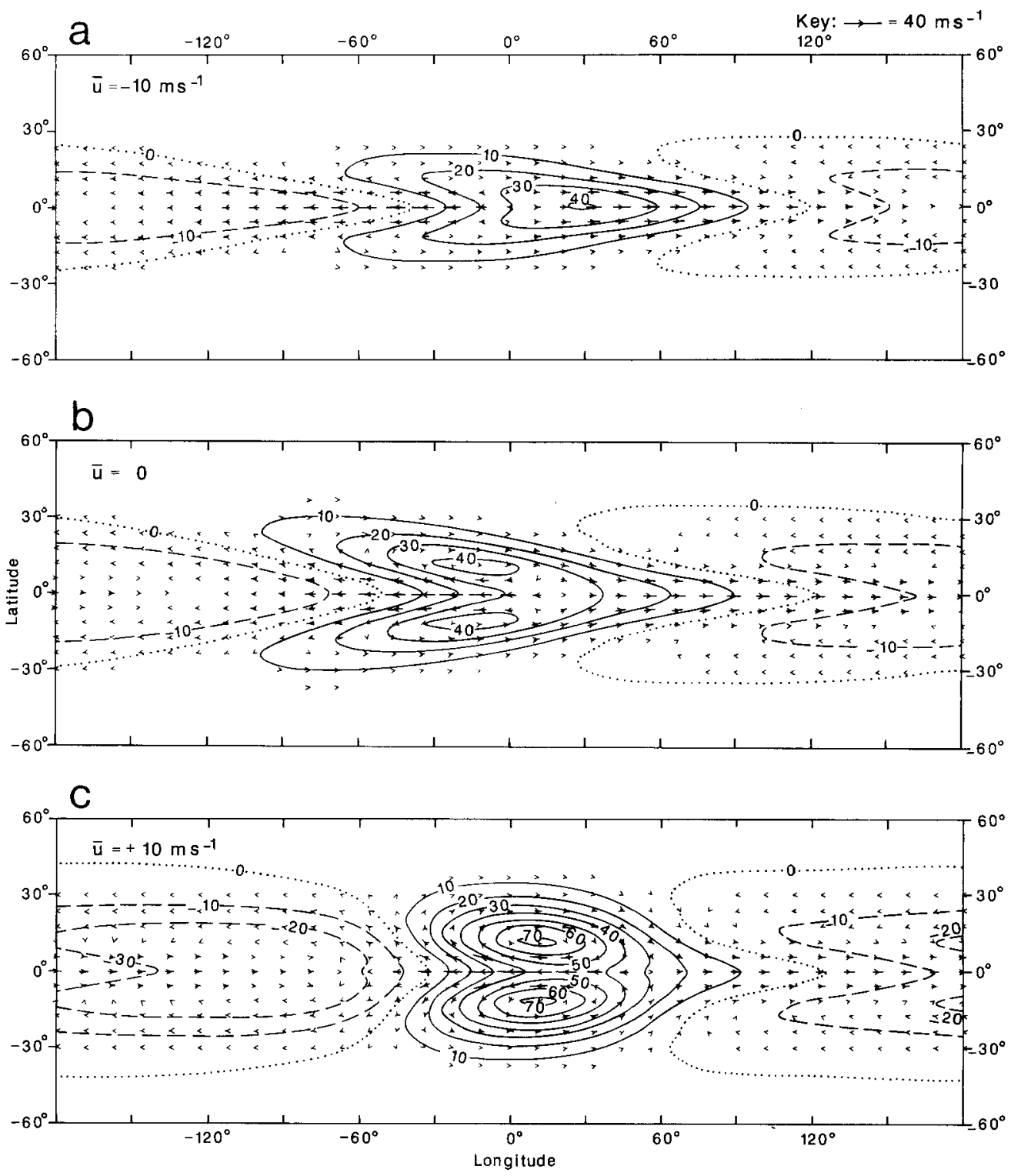

Figure 1. The linear model response at $300 \mathrm{mb}$ to an isolated heating of Gaussian spatial shape (see text) centred at $0^{\circ}$ longitude on the equator, and linearized about a uniform zonal current of: (a) $-10 \mathrm{~m} / \mathrm{s}$; (b) $0 \mathrm{~m} / \mathrm{s}$; and (c) $+10 \mathrm{~m} / \mathrm{s}$. Isolines are geopotential height (contour interval $10 \mathrm{gpm}$ ), and arrows the isobaric wind.

Lim and Chang 1983; Phlips and Gill 1987). Several further experiments have been made to ensure that the model behaves correctly and that the resolution is sufficient. The effect of increasing the dissipation is to weaken the circulation and to limit the east-west extent of the response as discussed by Phlips and Gill. In addition, increased dissipation decreases the relative importance of the $\beta$ effect near the equator, making the response more isotropic. The effect of linearizing about a realistic zonal-mean flow is to produce a far-field barotropic teleconnection response as discussed by Simmons (1982). 


\section{Simple MOdel Versus GCM}

Even in the tropics, the atmospheric circulation on the monthly time scale has a large natural variability. Thus, monthly-average fields obtained from GCM runs with the same, fixed s.s.t. distribution will vary from run to run, so that several integrations are needed to obtain stable climatologies. In this work, five independent February runs in control conditions (climatological s.s.t. distribution) are available for both GCMs, so that mean climatic conditions are fairly well established. Nonetheless, the problem arises as to how to compare the deterministic prediction of our simple model with a GCM climatology that has a substantial variability. Since the comparison must be evaluated at grid points which are highly correlated with one another, the comparison should be done using multivariate statistics. However, the multivariate problem cannot be handled directly because our sample size of GCM runs is much smaller than the number of grid points at which the comparison must be carried out, leading to a highly degenerate statistical problem. The dimensionality must therefore be strongly reduced, which is done here using a hypothesis-testing strategy as in Hannoschöck and Frankignoul (1985). By projecting the GCM climate onto the simple model's prediction, the problem reduces to a univariate test on the projection parameter. It can then be easily established whether it is significantly different from zero, and thus whether the GCM climate is consistent with linear theory, taking into account explicitly the GCM's variability.

Let the monthly mean of a variable or an ensemble of variables in run $n$ of a GCM be represented by a $q$-dimensional vector $\mathbf{X}(n)$. If an overbar denotes the sample mean over all $N$ runs and $\mathbf{P}$ represents a simple model's prediction of $\overline{\mathbf{X}}$, then we set

$$
\overline{\mathbf{X}}=\gamma \mathbf{P}+\mathbf{r} .
$$

Here $\gamma$ is the projection parameter, which is obtained by minimizing the magnitude of the residual, $\mathbf{r}$, yielding $\gamma=\mathbf{P}^{\prime} \cdot \overline{\mathbf{X}} /|\mathbf{P}|^{2}$, where a prime denotes the transpose vector. The interval in which the 'true' projection parameter, $\langle\gamma\rangle$, has a given probability of occurring can be estimated if $\overline{\mathbf{X}}$ is assumed to have a multivariate normal distribution, in which case $\gamma$, being a linear combination of normal variables, is also normally distributed. (Note that slight deviations from multinormality in the GCM fields are unlikely to cause a corresponding non-normality in $\gamma$, by the central limit theorem applied to (7).) We thus consider the test statistic

$$
T=(\gamma-\langle\gamma\rangle) /\left\{(1 / N)^{1 / 2} \Gamma^{1 / 2}\right\}
$$

where $\Gamma=\mathbf{P}^{\prime} \mathbf{S P} /|\mathbf{P}|^{4}$, and $\mathbf{S}$ is the covariance matrix, estimated by

$$
\mathbf{S}=\frac{1}{N-1} \sum_{n=1}^{N}\{\mathbf{X}(n)-\overline{\mathbf{X}}\}\{\mathbf{X}(n)-\overline{\mathbf{X}}\}^{\prime} .
$$

When $\langle\gamma\rangle=0, T$ is a $t$-random variable with $\nu=N-1$ degrees of freedom. Since the response magnitude can be more easily tuned in a linear model than the response pattern by changing the dissipation, we first test whether $\langle\gamma\rangle$ is different from zero (one-sided test). The calculation can also be used to estimate the $95 \%$ confidence interval for $\langle\gamma\rangle$ (two-sided), which is given by

$$
\left\{\gamma-(\Gamma / N)^{1 / 2} t_{N-1,0.025}\right\} \leqslant\langle\gamma\rangle \leqslant\left\{\gamma+(\Gamma / N)^{1 / 2} t_{N-1,0.025}\right\}
$$

and allows us to test whether the linear model amplitude is appropriate, i.e. $\langle\gamma\rangle=1$.

This test indicates whether the GCM data are consistent, at a given level of significance, with the linear model response to the prescribed heating. This neglects the variability in the heating field as it does not affect the mean response of a linear model. 
However, the estimation of statistical significance may be biased, if a substantial part of the GCM variability is associated with variability in the diabatic heating itself. A different question is how much of the GCM signal is explained by the linear model. From (7), we can estimate the proportion of the spatial variance of the GCM signal that can be predicted by the linear model. It may be regarded as the 'skill' of the linear model, and is given by

$$
s=1-|\mathbf{r}|^{2} /|\overline{\mathbf{X}}|^{2} .
$$

Rather limited values of the skill are found below. However, visual perception is sensitive to amplitudes rather than to variances, so that $s^{1 / 2}$ corresponds more to an intuitive goodness-of-fit measure.

\section{Simulation of the Giss february climatology}

The GISS model 2 is an efficient low-resolution model $\left(8 \times 10^{\circ}\right.$ grid, $9 \sigma$-layers $)$ designed primarily for long-term climate integrations. As discussed by Hansen et al. (1983), the model reproduces realistically the main features of the atmospheric circulation. The climatology used consists of mean quantities for February, taken from a single 5-year control run, in which daily climatological s.s.t. conditions were applied.

Our aim is to simulate the zonal asymmetries of the GCM climatology in the tropics (i.e. the Walker circulation), by forcing our simple model with the zonal asymmetries of the GCM's tropical diabatic heating climatology. For this purpose, we taper the forcing to zero in the extratropics, using a cosine(latitude) factor between 20 and $40^{\circ}$ latitude. Care was taken to conserve the vertically integrated heating when interpolating from the GCM's layer-average diabatic heating rates onto those of the simple model. Figure 2 shows the mean interpolated diabatic heating asymmetries at 400 and $900 \mathrm{mb}$, which refer to the layers $300-500 \mathrm{mb}$ and $850-1000 \mathrm{mb}$ respectively. The field has a maximum at $400-600 \mathrm{mb}(1-2 \mathrm{~K} / \mathrm{d})$ in the tropics with decreasing magnitudes below; these are rather smaller magnitudes than one would expect at middle levels in the tropics. At $900 \mathrm{mb}$, regions of cooling tend to underlie the mid-tropospheric equatorial heating regions over southern Africa and South America. This is due to re-evaporation of rain
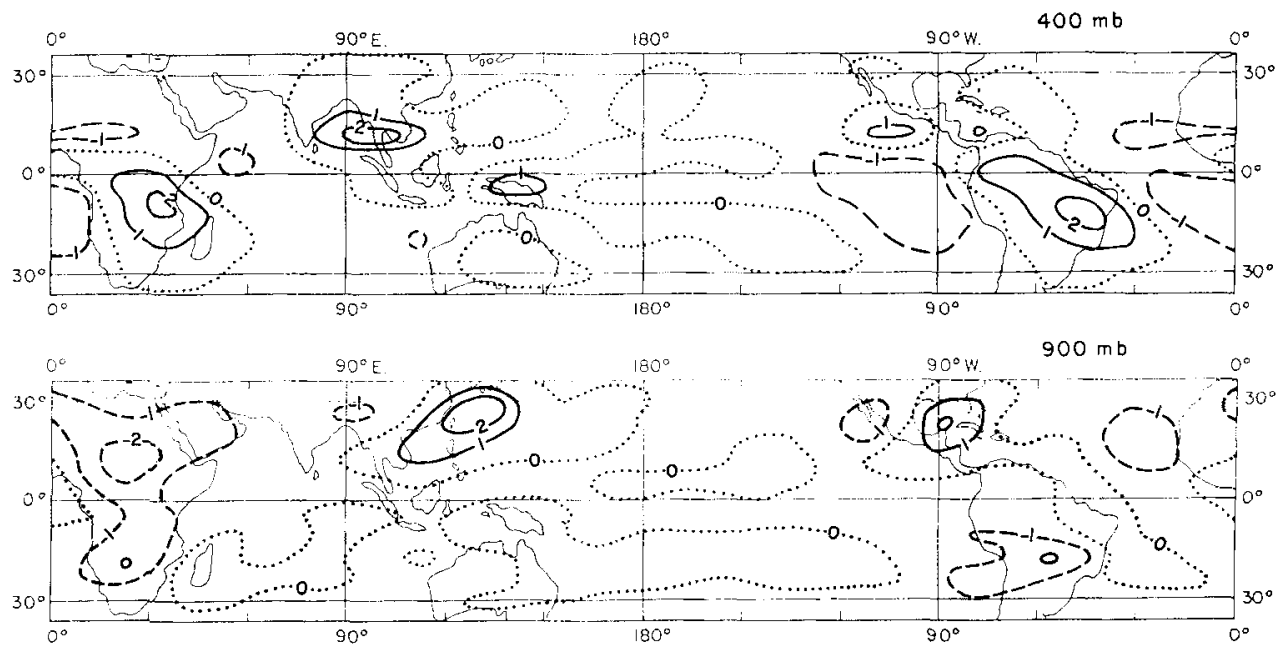

Figure 2. The GISS diabatic heating zonal asymmetries between $30^{\circ} \mathrm{N}$ and $30^{\circ} \mathrm{S}$ (5-Februaries mean), interpolated onto the linear model grid at $400 \mathrm{mb}$ (top), and $900 \mathrm{mb}$ (bottom). Contour interval $1 \mathrm{~K} / \mathrm{d}$. 

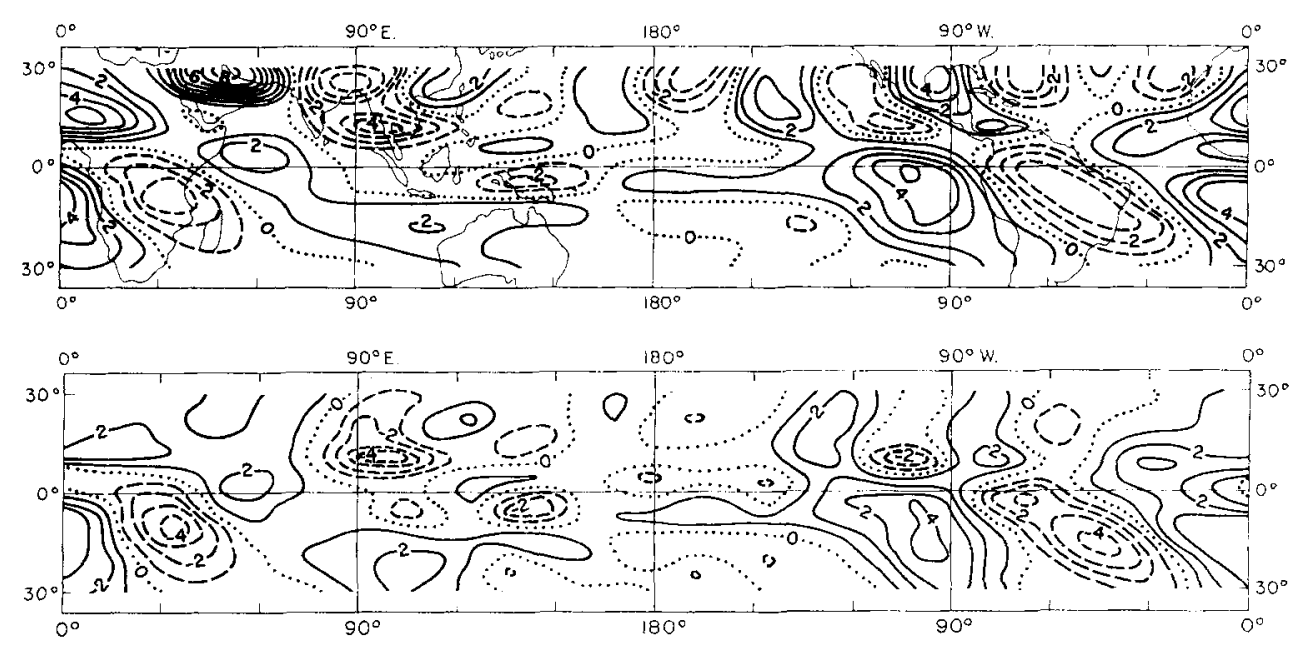

Figure 3. Omega at $400 \mathrm{mb}$ between $30^{\circ} \mathrm{N}$ and $30^{\circ} \mathrm{S}$. Top: GISS (5-Februaries-mean zonal asymmetries), and bottom: linear simulation. Contour interval $10^{-4} \mathrm{mb} \mathrm{s}^{-1}$.

falling through the lower of the two layers representing the boundary layer in the GISS model (as discussed by Yao and Stone (1987), this feature is associated with the low spatial resolution). Such a vertical heating structure cannot be well represented in our model by the integrated value at $900 \mathrm{mb}$. We thus cannot expect the linear model to simulate the GISS GCM properly near the surface.

The simple model was linearized about the full three-component zonally averaged GISS model climatological flow and temperature distribution. The simulated omega field, together with that of the GCM (all GCM fields shown have the zonal mean removed) at $400 \mathrm{mb}$ is shown in Fig. 3. There is a very close correspondence, both in magnitude and phase, between the two away from orography and south of $15^{\circ} \mathrm{N}$ (except over West Africa), where the effects of horizontal temperature gradients and orography are presumably small. This results from the essentially linear balance in the thermodynamic equation in the tropics between diabatic heating and adiabatic cooling associated with ascending motion (e.g. Hoskins and Karoly 1981). The comparison between the horizontal wind fields at $300 \mathrm{mb}$ and $850 \mathrm{mb}$ is shown in Fig. 4. The much poorer comparison is obvious, especially at $300 \mathrm{mb}$ north of $10^{\circ} \mathrm{N}$, where the winter stationary waves (which are strongly orographically forced in part) and the transients are prominent. Near the equator east of the date line however, especially at $850 \mathrm{mb}$, the simple model simulation looks quite reasonable. At $950 \mathrm{mb}$, the lowest model layer (not shown), the comparison is poor.

In order to quantify the simple model's performance, we project the GCM climatology onto the simulation as detailed in section 3 . Since it is desirable to have the best measure of the variability inherent in the climatology, ten additional February integrations from s.s.t. sensitivity experiments were also used in calculating the covariance matrix S. These integrations, discussed in Frankignoul and Molin (1988a, b), were designed to investigate the influence of rather moderate s.s.t. anomalies located in the North Pacific and subtropical Pacific respectively. Their influence was small and it is likely that they influence the variability in the tropics little. These extra runs enable us to use a Student $t$-test with 12 degrees of freedom. The analysis was carried out one level at a time for the fields of omega and the horizontal wind separately, so that $\overline{\mathbf{X}}$ and $\mathbf{P}$ in (7) consist of $\omega$ or $\mathbf{v}=u \mathbf{i}+v \mathbf{j}$ at each latitude for zonal wavenumbers 1 to 8 . We restrict 

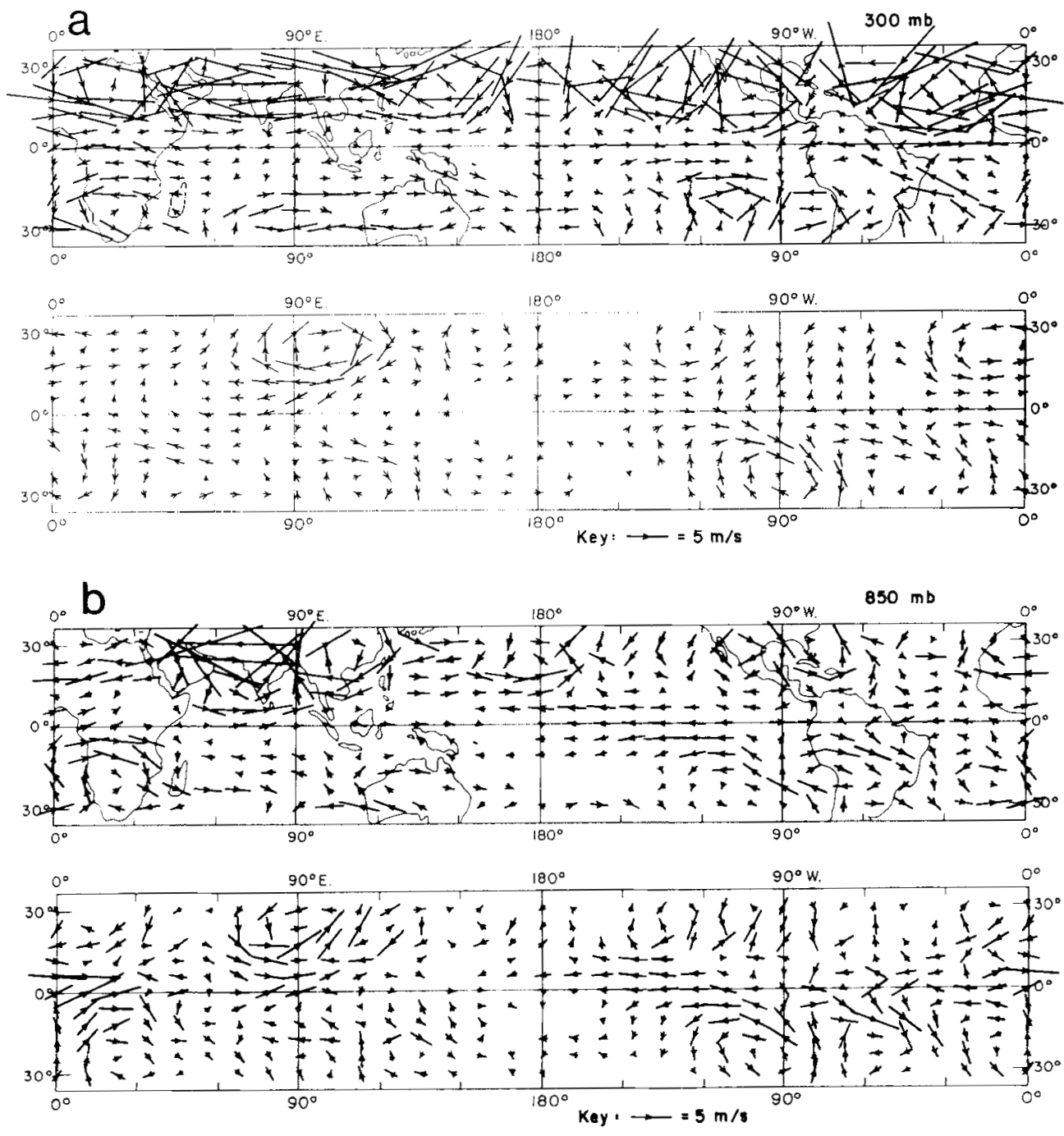

Figure 4. As Fig. 3, but for the horizontal wind vectors at: (a) $300 \mathrm{mb}$; and (b) $850 \mathrm{mb}$.

the comparison to the latitude band $15^{\circ} \mathrm{N}-30^{\circ} \mathrm{S}$, consistent with the seasonal position of the Hadley cell, so as to minimize extratropical effects in the winter hemisphere and to avoid the Himalayas. The results are summarized in Fig. 5, which shows $95 \%$ confidence limits for $\langle\gamma\rangle$ together with the linear model skill.

At the $2.5 \%$ level of significance, the null hypothesis, $\langle\gamma\rangle=0$, that the simulation is inconsistent with the GCM, can be rejected at all levels for both $\omega$ and $\mathbf{v}$. In fact with the exception of $\mathbf{v}$ at middle levels $(500$ and $700 \mathrm{mb})$, the null hypothesis can be rejected everywhere at the $0.5 \%$ level, which stresses the usefulness of the linear model in reproducing the GCM's zonal asymmetries. Regarding the $\omega$ field, the linear prediction has the correct amplitude with values of $\gamma$ very close to one, and it accounts for over $85 \%$ of the GCM spatial variance, confirming the excellent agreement seen in Fig. 3. However, the agreement is poorer at $900 \mathrm{mb}$ where it is likely that the linear model cannot handle the sign reversal in the diabatic heating field at low levels in the GISS model, as discussed earlier. 

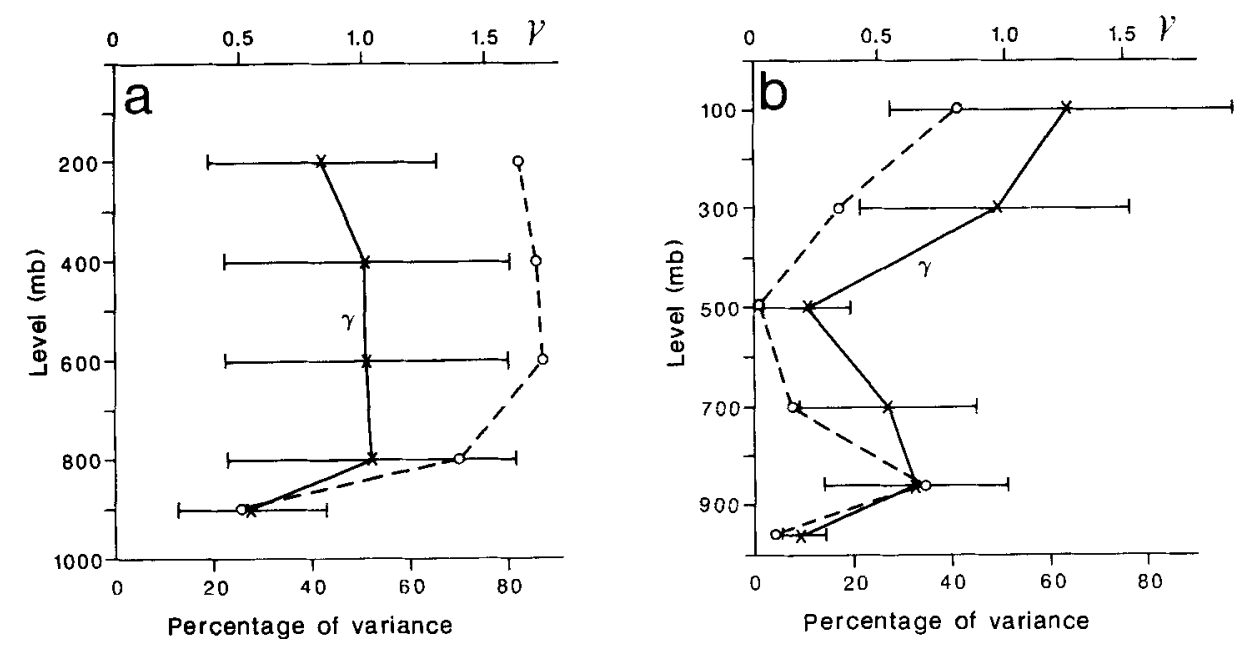

Figure 5. Statistical comparison of the linear simulation of the GISS climatology, for: (a) the omega field; and (b) the horizontal wind. Crosses joined by thick solid lines denote values of $\gamma$ (non-dimensional) at each model level. Error bars show the $95 \%$ confidence interval for the true value of $\gamma,\langle\gamma\rangle$. Circles joined by the dashed lines indicate the percentage of the spatial variance, $s$, explained by the simulation at each level.

In the case of the $\mathbf{v}$ field, the linear model tends to overestimate the magnitude of the mean zonal asymmetries, except at high levels, and the skills are lower. Agreement is poor in the mid troposphere, presumably owing to the first-baroclinic-mode character of the linear response to latent heating, which implies zero wind at mid-levels and a low signal-to-noise ratio. At $850 \mathrm{mb}$, the linear prediction has nearly the right magnitude and $\langle\gamma\rangle=1$ is within the $95 \%$ confidence limits, but the skill remains rather small. At $950 \mathrm{mb}$ the linear model prediction is poor, as expected.

Altogether, the spatial variance of $\mathbf{v}$ explained reaches a maximum of only $30-$ $40 \%$ and then only at 850 and $100 \mathrm{mb}$. These results demonstrate the large degree of nonlinearity in the momentum balance, and show that the predictive skill of the linear model is limited.

Several sensitivity experiments were performed and the main results are summarized in Table 1. As discussed in section 2, a frictional damping configuration with a very uniform effect throughout the tropics is employed in the standard version. The results were not found to be very sensitive to halving or doubling this effect, or to similar changes in boundary-layer drag or the rate of Newtonian cooling. However, when the strong dissipation was applied only in the regions of critical lines, such as with the formulation of Simmons (1982), the simulation deteriorated substantially for the horizontal velocity (experiment 2 in Table 1). Similarly, uniform Rayleigh friction and Newtonian cooling (with time scales of 5 and 15 days respectively), caused marked decreases in skill (experiment 3). These results underline the importance of strong uniform damping in the tropics in addition to that used to parametrize critical lines, and lend support to the formulation of Nigam et al. (1986). The influence of the basic state flow was also investigated. The prediction of the horizontal velocity was found to be very insensitive to suppression of the mean meridional circulation (experiment 4), though the simulation of $\omega$ improved slightly near the ground. However, the difference may not be significant. On the other hand, there is more sensitivity to the zonal component of the mean wind (experiment 5), even though its effect varies from level to level.

As the agreement with the GISS climatology is limited and the error bars are large, a finer tuning was not attempted. Note that relatively small signal-to-noise ratios may 
TABLE 1. Simulation OF GISS Climatology WITH LINEAR MOdEL: VAlues OF $\gamma$, AND $s$, FOR VARIOUS EXPERIMENTS

\begin{tabular}{|c|c|c|c|c|c|}
\hline Experiment & $\begin{array}{c}\text { (1) } \\
\text { Standard }\end{array}$ & $\begin{array}{l}(2) \\
\text { Simmons } \\
\text { friction }\end{array}$ & $\begin{array}{c}(3) \\
\text { Uniform } \\
\text { dissipation }\end{array}$ & $(\bar{V}, \bar{\omega})=0$ & $(\bar{U}, \bar{V}, \bar{\omega})=0$ \\
\hline \multicolumn{6}{|l|}{$\begin{array}{l}\text { Level } \\
\text { (mb) }\end{array}$} \\
\hline \multicolumn{6}{|c|}{ Horizontal wind } \\
\hline 100 & $\begin{array}{l}1 \cdot 24 \\
(41)\end{array}$ & $\begin{array}{l}0.51 \\
(24)\end{array}$ & $\begin{array}{l}\mathbf{0 . 6 7} \\
(21)\end{array}$ & $\begin{array}{l}1.22 \\
(41)\end{array}$ & $\begin{array}{l}2 \cdot 68 \\
(33)\end{array}$ \\
\hline 300 & $\begin{array}{l}0.96 \\
(17)\end{array}$ & $\begin{array}{l}0.63 \\
(19)\end{array}$ & $\begin{array}{l}0.64 \\
(15)\end{array}$ & $\begin{array}{l}\mathbf{0 . 9 2} \\
(17)\end{array}$ & $\begin{array}{l}1 \cdot 17 \\
(33)\end{array}$ \\
\hline 500 & $\begin{array}{c}0 \cdot 22 \\
(0)\end{array}$ & $\begin{array}{l}0 \cdot(07 \\
(0)\end{array}$ & $\begin{array}{c}0 \cdot(08 \\
(0)\end{array}$ & $\begin{array}{c}0 \cdot 19 \\
(0)\end{array}$ & $\begin{array}{l}0.46 \\
(2)\end{array}$ \\
\hline 700 & $\begin{array}{c}0.53 \\
(8)\end{array}$ & $\begin{array}{c}0-12 \\
(2)\end{array}$ & $\begin{array}{c}0.01 \\
(0)\end{array}$ & $\begin{array}{c}0.48 \\
(8)\end{array}$ & $\begin{array}{l}0.65 \\
(10)\end{array}$ \\
\hline 850 & $\begin{array}{l}0.64 \\
(34)\end{array}$ & $\begin{array}{l}0.39 \\
(19)\end{array}$ & $\begin{array}{l}0.21 \\
(21)\end{array}$ & $\begin{array}{l}\mathbf{0 . 6 4} \\
(33)\end{array}$ & $\begin{array}{l}0.57 \\
(23)\end{array}$ \\
\hline 950 & $\begin{array}{l}0 \cdot 19 \\
(4)\end{array}$ & $\begin{array}{l}0 \cdot 15 \\
(4)\end{array}$ & $\begin{array}{c}0.06 \\
(6)\end{array}$ & $\begin{array}{c}0.26 \\
(6)\end{array}$ & $\begin{array}{l}0 \cdot 26 \\
(4)\end{array}$ \\
\hline \multicolumn{6}{|l|}{ Omega } \\
\hline 200 & $\begin{array}{l}\mathbf{0 . 8 2} \\
(82)\end{array}$ & $\begin{array}{l}\mathbf{0 . 7 9} \\
(82)\end{array}$ & $\begin{array}{l}0.67 \\
(65)\end{array}$ & $\begin{array}{l}0.82 \\
(83)\end{array}$ & $\begin{array}{l}0.91 \\
(80)\end{array}$ \\
\hline 400 & $\begin{array}{l}\mathbf{1 . 0 0} \\
(86)\end{array}$ & $\begin{array}{l}0 \cdot 93 \\
(80)\end{array}$ & $\begin{array}{l}\mathbf{0 . 8 8} \\
(72)\end{array}$ & $\begin{array}{l}1.00 \\
(86)\end{array}$ & $\begin{array}{l}\mathbf{1 . 0 6} \\
(87)\end{array}$ \\
\hline 600 & $\begin{array}{l}\mathbf{1 \cdot 0 0} \\
(87)\end{array}$ & $\begin{array}{l}\mathbf{0 . 9 0} \\
(81)\end{array}$ & $\begin{array}{l}0.83 \\
(74)\end{array}$ & $\begin{array}{l}\mathbf{1 . 0 1} \\
(87)\end{array}$ & $\begin{array}{l}\mathbf{1 . 0 8} \\
(86)\end{array}$ \\
\hline 800 & $\begin{array}{l}1.01 \\
(70)\end{array}$ & $\begin{array}{l}0.93 \\
(66)\end{array}$ & $\begin{array}{l}0 \cdot 79 \\
(64)\end{array}$ & $\begin{array}{l}\mathbf{1 . 0 9} \\
(76)\end{array}$ & $\begin{array}{l}1 \cdot 10 \\
(70)\end{array}$ \\
\hline 900 & $\begin{array}{l}0.54 \\
(26)\end{array}$ & $\begin{array}{l}0.53 \\
(33)\end{array}$ & $\begin{array}{l}0.40 \\
(23)\end{array}$ & $\begin{array}{l}0.72 \\
(38)\end{array}$ & $\begin{array}{l}0.69 \\
(29)\end{array}$ \\
\hline
\end{tabular}

Key: bold face indicates that the $95 \%$ confidence interval for the true gamma, $\langle\gamma\rangle$, includes the expected value $\langle\gamma\rangle=1$; normal face that the interval includes neither 0 nor 1 ; and italic that it includes $\langle\gamma\rangle=0$ (model not statistically significant). In brackets is the spatial variance explained, as a percentage (s). The experiments are: (1) standard simulation for comparison; (2) as (1), but Rayleigh friction in the free atmosphere confined to vicinity of critical lines (Simmons 1982); (3) as (1), but with uniform Rayleigh friction and Newtonian cooling, with damping time scales of 5 and 15 days respectively; (4) as (1), but with $(\bar{V}, \bar{\omega})=0$ (mean meridional circulation suppressed); (5) as (1), but linearized about a motionless basic state.

result from the GISS model's underestimate of the amplitude of the zonally asymmetric component of the flow, and from its slight excess of transient eddy kinetic energy.

\section{Simulation of the LMD February climatology}

The LMD model is a high-resolution GCM which has been described in Sadourny and Laval (1984). It has 50 latitudes equidistant in sine(latitude) (amounting to better than $2 \cdot 4^{\circ}$ equatorward of $30^{\circ}$ ), 64 points in longitude (i.e. $5 \cdot 6^{\circ}$ at the equator), and 11 $\sigma$-layers in the vertical (the lowest 4 layers represent the boundary layer, which is well resolved). The climatology used consists of the mean of five control February runs (started from observed conditions on the first day of five different Januaries) in which s.s.t.s had their daily climatological values. Two additional February runs (started 

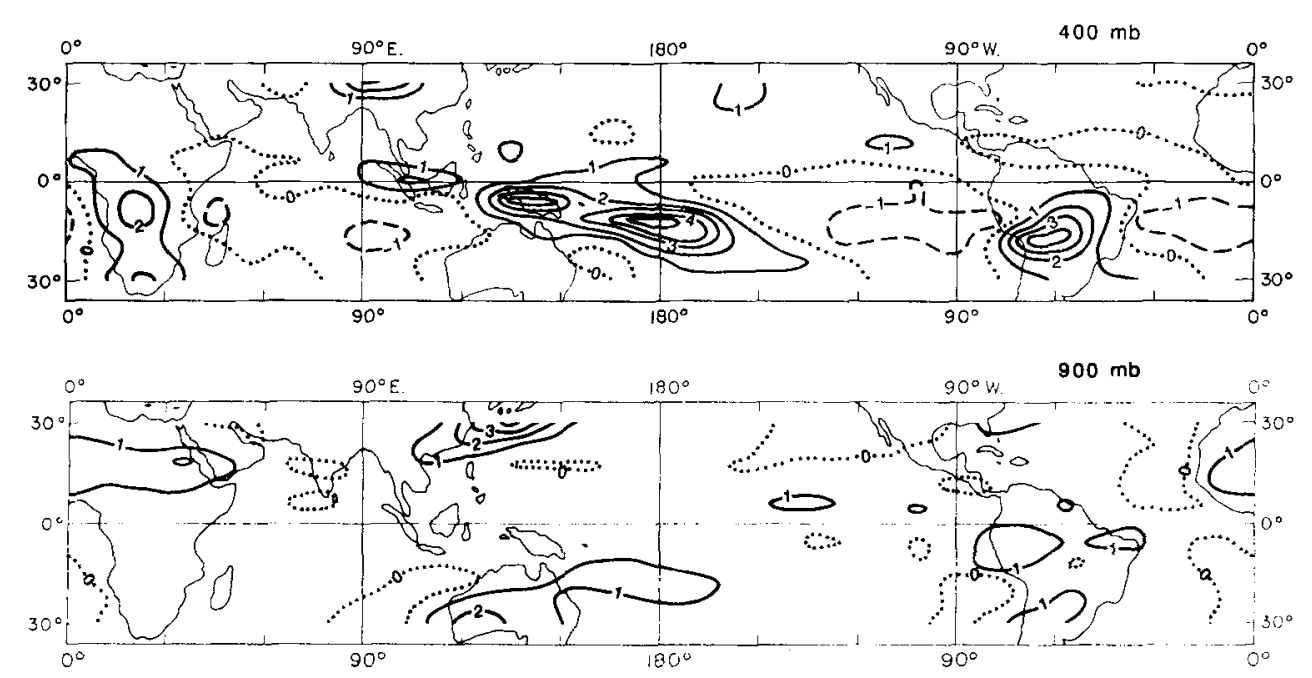

Figure 6. The LMD diabatic heating climatology, as Fig. 2.

similarly) with an anomalous s.s.t. of the composite 'El Niño' type added (Rasmussen and Carpenter 1982), were available for use in the variance calculations. These integrations are described in Lopez de Arias (1988).

The procedure followed in section 4 is repeated here using the LMD climatology, whose mean zonally-asymmetric heating field is shown at 400 and $900 \mathrm{mb}$ in Fig. 6. It is clear that the LMD model has a much more intense hydrological cycle and Walker circulation (Fig. 7) than the GISS model, with a strong South Pacific convergence zone (SPCZ). The vertical distribution of diabatic heating (not shown) is realistic in the tropics, showing a maximum around $400 \mathrm{mb}$ and a slow decrease toward the ground. The absence of a sign reversal near the ground suggests that the linear model will have less difficulty in reproducing the mean surface wind, as indeed is shown below to be the case.

Figure 7 shows the $400 \mathrm{mb}$ omega fields for the LMD climatology and the linear simulation, and Fig. 9(a) summarises the quantitative comparison in terms of $\gamma$ and $s$.
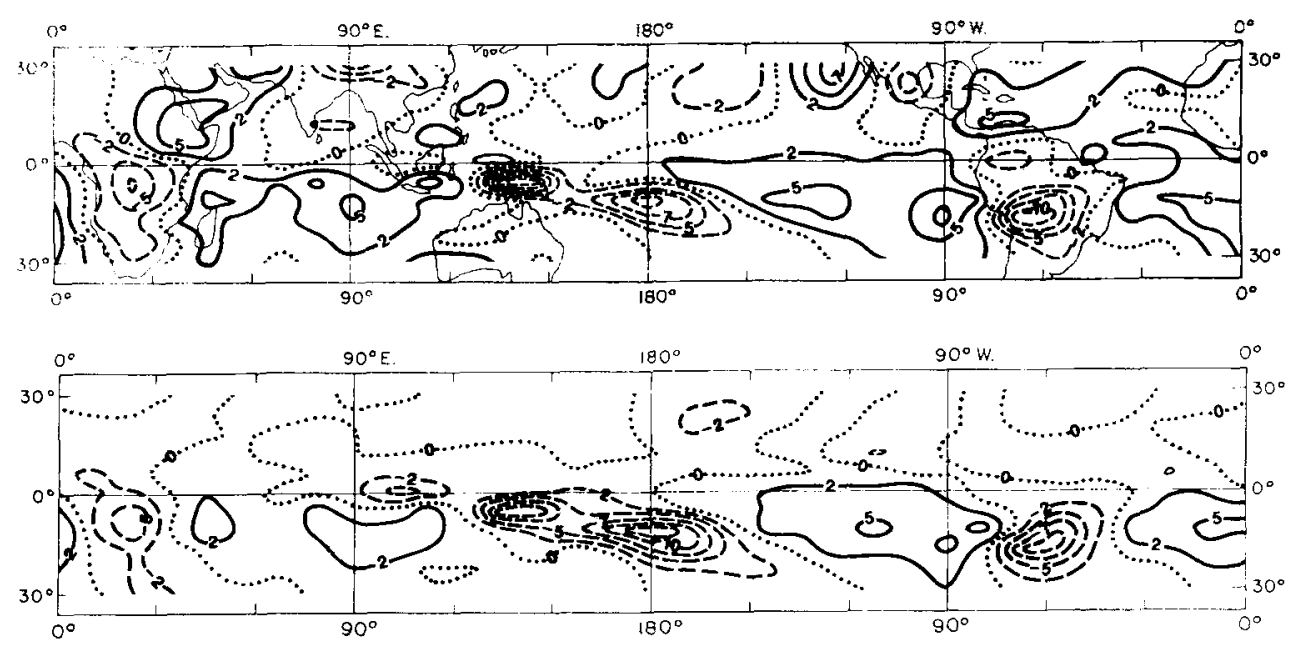

Figure 7. Simulation of the LMD omega field at $400 \mathrm{mb}$, as Fig. 3. Contour interval $2.5 \times 10^{-4} \mathrm{mb} \mathrm{s}^{-1}$. 
As in the GISS case, the agreement for $\omega$ is excellent (although slightly inferior) both in magnitude and phase, in particular south of $15^{\circ} \mathrm{N}$ and away from orography. The horizontal wind comparison is illustrated in Fig. 8 at 300 and $950 \mathrm{mb}$, and documented in Fig. 9(b). Again the agreement is poorer than for the omega field, but the skill is somewhat higher than in the GISS case, in particular at $950 \mathrm{mb}$ where a maximum of $42 \%$ is reached. The good agreement near the ground, though contrasting with the GISS case, is consistent with our expectation that the assumption of linearity should be most valid at the lowest levels, where nonlinearities and transients have a smaller effect on the momentum and vorticity balance. This better agreement also confirms our hypothesis that the linear model is unable to represent the particular vertical structures of the lowlevel heating in the GISS GCM.

Noteworthy in Fig. 9 is that the 95\% confidence intervals for $\gamma$ are smaller than in the GISS case (especially for $\omega$ ), even though only 5 degrees of freedom were available
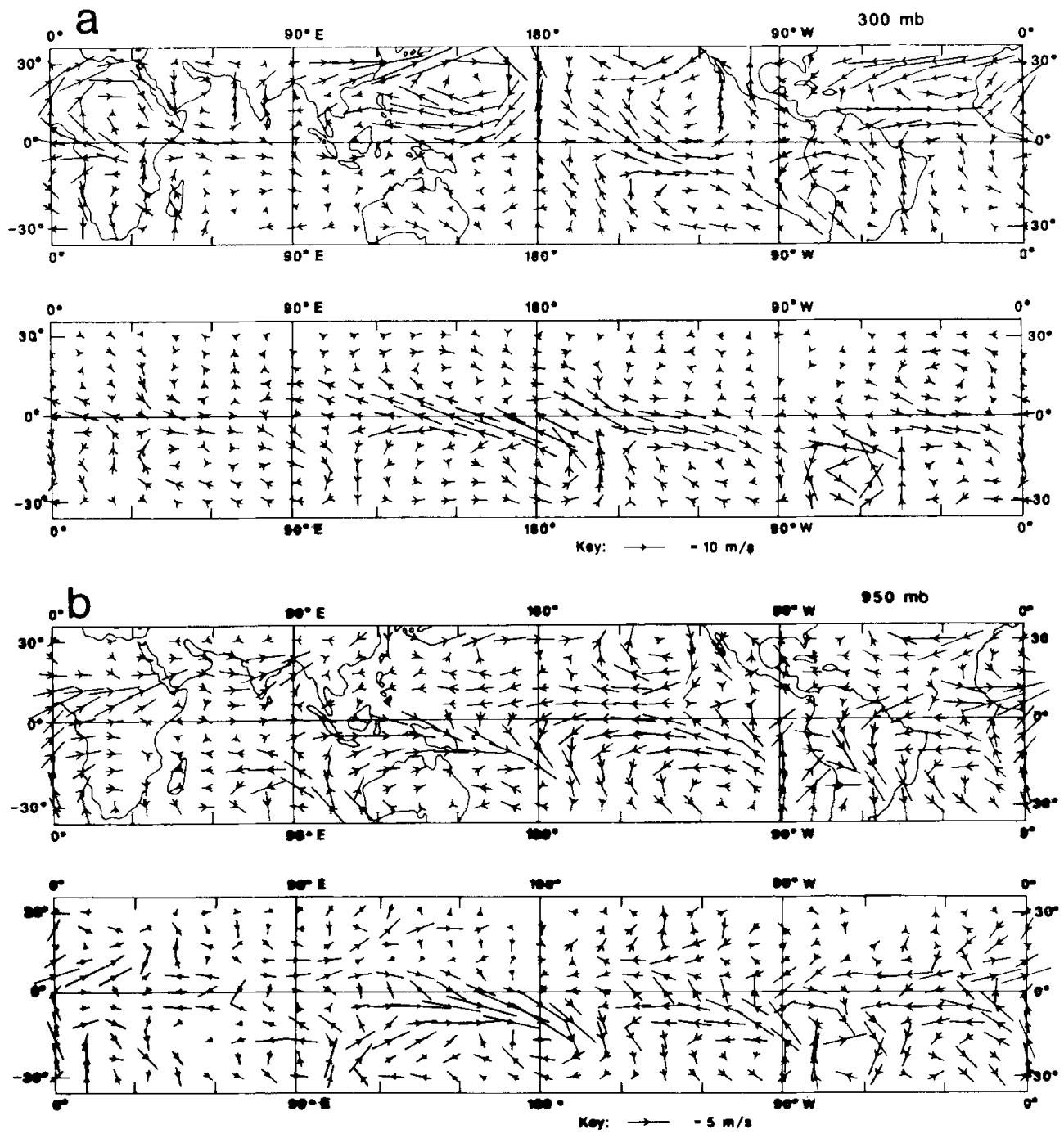

Figure 8. Linear simulation of the LMD horizontal wind-vector field at: (a) $300 \mathrm{mb}$; and (b) $950 \mathrm{mb}$. As Fig. 4. 

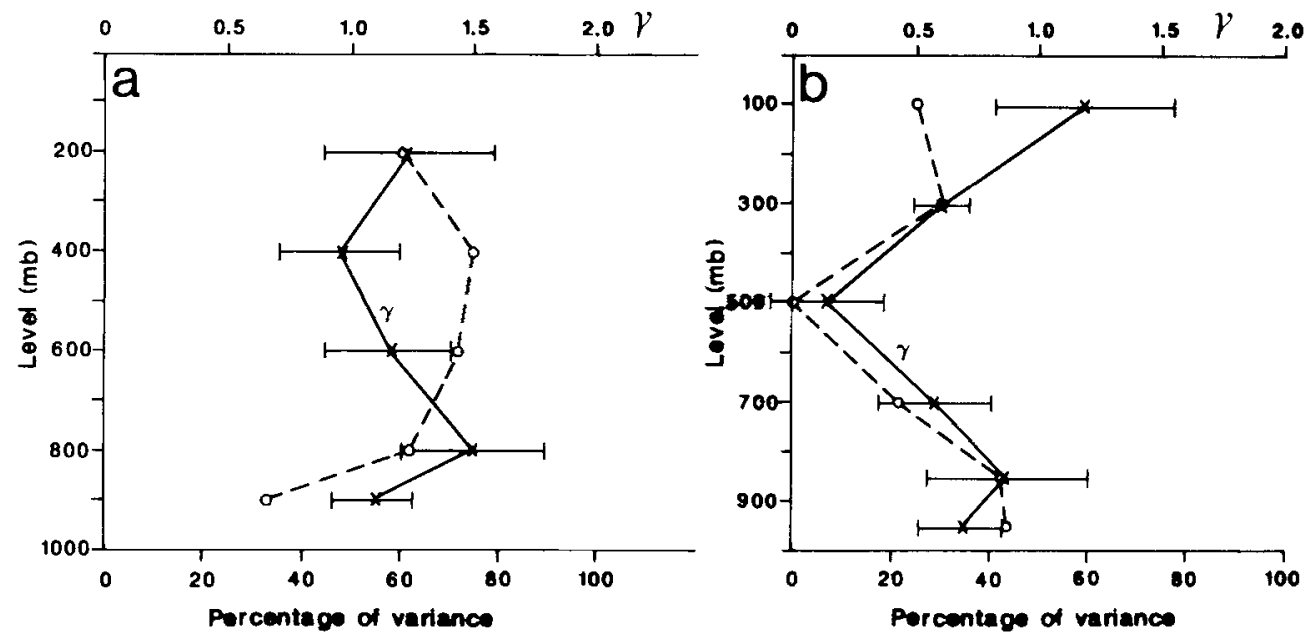

Figure 9. As Fig. 5, but for simulation of the LMD climatology.

in the estimate of the error covariance matrix. The larger signal-to-noise ratio in the LMD case is due to the larger zonally asymmetric component of the flow and the smaller variability, resulting generally in the rejection of the null hypothesis at a very low level. In fact, except at $500 \mathrm{mb}$ where the horizontal velocity in the linear model is inconsistent with that of the GCM, the null hypothesis is rejected at the $0.1 \%$ level of significance. The smaller error bars make it clear, however, that the linear prediction of $\mathbf{v}$ is generally overestimated in the lower troposphere ( $\langle\gamma\rangle$ smaller than one) with our standard choice of damping parametrization. Some model tuning is thus necessary.

The sensitivity of the simulation to the basic state is summarized in Table 2 . Experiment 2 illustrates the effect of setting the mean meridional circulation (MMC) to zero: the changes in skill are very small, and probably not significant. Thus, as in the GISS case, advection by the MMC is unimportant. In experiment 3 the simple model is linearized about a motionless basic state. Here the results are clearly degraded for the horizontal velocity, with loss of all skill to simulate the $300 \mathrm{mb}$ wind. However, the skill is relatively little affected in the case of the omega field, as a consequence of the close linear balance between diabatic heating and adiabatic cooling. These results confirm the importance of advection by the zonal component of the zonal-mean wind for the vorticity balance, especially at $300 \mathrm{mb}$ where the mean flow is strong, in agreement with Sardeshmukh and Hoskins (1985), but also near the surface. Contrasting results were found by Rosenlof et al. (1986) in a similar model which, however, included a simple cumulus-friction parametrization. They found that the mean zonal wind had only a very small influence on the tropical response to equatorial heating, whilst a MMC produced significant changes. This is probably due to the strong influence of cumulus friction in their model and its dependence on the MMC, and is not found in more sophisticated linear models.

The sensitivity of the agreement with the LMD climatology to changes in the dissipation parameters has been investigated in detail by Lopez de Arias (1988), and only the main results are reported here. As expected from the overestimation of the low-level wind in the linear model, an increase in the dissipation brings a better agreement in magnitude. The skills are little affected by the parameter changes, but an improvement in the model amplitude at one level may be accompanied by a slight decrease in skill. 
TABLE 2. SimUlation OF THE LMD Climatology WITH LINEAR MODEL: RESULTS OF SENSITIVITY EXPERIMENTS

\begin{tabular}{|c|c|c|c|c|c|c|}
\hline Experiment & $\begin{array}{c}\text { (1) } \\
\text { Standard }\end{array}$ & $\left(\bar{V}, \frac{(2)}{\omega}\right)=0$ & $(\bar{U}, \bar{V}, \bar{\omega})=0$ & $\begin{array}{c}(4) \\
\text { Optimal }\end{array}$ & $\begin{array}{c}\text { (5) } \\
\text { B.L. } \\
\text { heating }\end{array}$ & $\begin{array}{c}\text { (6) } \\
\text { Mid-trop. } \\
\text { heating }\end{array}$ \\
\hline \multicolumn{7}{|l|}{$\begin{array}{l}\text { Level } \\
(\mathrm{mb})\end{array}$} \\
\hline \multicolumn{7}{|c|}{ Horizontal wind } \\
\hline 100 & $\begin{array}{l}\mathbf{1} \cdot 19 \\
(25)\end{array}$ & $\begin{array}{l}1 \cdot 35 \\
(28)\end{array}$ & $\begin{array}{l}0.48 \\
(12)\end{array}$ & $\begin{array}{l}1 \cdot 39 \\
(26)\end{array}$ & $\begin{array}{r}19 \cdot 12 \\
(15)\end{array}$ & $\begin{array}{l}1.39 \\
(25)\end{array}$ \\
\hline 300 & $\begin{array}{l}0 \cdot 60 \\
(31)\end{array}$ & $\begin{array}{l}0.59 \\
(31)\end{array}$ & $\begin{array}{c}0.04 \\
(0)\end{array}$ & $\begin{array}{l}\mathbf{0 . 9 2} \\
(22)\end{array}$ & $\begin{array}{c}6.25 \\
(6)\end{array}$ & $\begin{array}{l}0.93 \\
(22)\end{array}$ \\
\hline 500 & $\begin{array}{c}0.14 \\
(0)\end{array}$ & $\begin{array}{c}0.04 \\
(0)\end{array}$ & $\begin{array}{c}0.01 \\
(0)\end{array}$ & $\begin{array}{c}0 \cdot 16 \\
(0)\end{array}$ & $\begin{array}{c}0.22 \\
(0)\end{array}$ & $\begin{array}{c}0 \cdot 12 \\
(0)\end{array}$ \\
\hline 700 & $\begin{array}{l}0 \cdot 58 \\
(22)\end{array}$ & $\begin{array}{l}0.57 \\
(21)\end{array}$ & $\begin{array}{c}0 \cdot 13 \\
(6)\end{array}$ & $\begin{array}{l}\mathbf{0 \cdot 7 5} \\
(16)\end{array}$ & $\begin{array}{c}0.03 \\
(0)\end{array}$ & $\begin{array}{c}0 \cdot 39 \\
(8)\end{array}$ \\
\hline 850 & $\begin{array}{l}\mathbf{0 . 8 8} \\
(42)\end{array}$ & $\begin{array}{l}0 \cdot 85 \\
(42)\end{array}$ & $\begin{array}{l}0 \cdot 42 \\
(21)\end{array}$ & $\begin{array}{l}1 \cdot 14 \\
(37)\end{array}$ & $\begin{array}{l}1 \cdot 76 \\
(28)\end{array}$ & $\begin{array}{l}1 \cdot 75 \\
(29)\end{array}$ \\
\hline 950 & $\begin{array}{l}0.69 \\
(43)\end{array}$ & $\begin{array}{l}0.69 \\
(45)\end{array}$ & $\begin{array}{l}0.48 \\
(29)\end{array}$ & $\begin{array}{l}1.06 \\
(44)\end{array}$ & $\begin{array}{l}1.41 \\
(40)\end{array}$ & $\begin{array}{l}2 \cdot 04 \\
(27)\end{array}$ \\
\hline \multicolumn{7}{|l|}{ Omega } \\
\hline 200 & $\begin{array}{l}\mathbf{1 . 2 4} \\
(62)\end{array}$ & $\begin{array}{l}1 \cdot 27 \\
(63)\end{array}$ & $\begin{array}{l}1 \cdot 28 \\
(58)\end{array}$ & $\begin{array}{l}1 \cdot 30 \\
(66)\end{array}$ & $\begin{array}{r}18 \cdot 26 \\
(12)\end{array}$ & $\begin{array}{l}1 \cdot 31 \\
(66)\end{array}$ \\
\hline 400 & $\begin{array}{l}\mathbf{0 . 9 6} \\
(75)\end{array}$ & $\begin{array}{l}\mathbf{0 . 9 7} \\
(76)\end{array}$ & $\begin{array}{l}\mathbf{0} 88 \\
(65)\end{array}$ & $\begin{array}{l}1 \cdot 07 \\
(74)\end{array}$ & $\begin{array}{l}6 \cdot 22 \\
(3)\end{array}$ & $\begin{array}{l}\mathbf{1 . 0 8} \\
(74)\end{array}$ \\
\hline 600 & $\begin{array}{l}1 \cdot 16 \\
(73)\end{array}$ & $\begin{array}{l}1 \cdot 15 \\
(72)\end{array}$ & $\begin{array}{l}1 \cdot 06 \\
(65)\end{array}$ & $\begin{array}{l}\mathbf{1 . 2 4} \\
(71)\end{array}$ & $\begin{array}{l}8 \cdot 08 \\
(28)\end{array}$ & $\begin{array}{l}1 \cdot 32 \\
(71)\end{array}$ \\
\hline 800 & $\begin{array}{l}1 \cdot 51 \\
(62)\end{array}$ & $\begin{array}{l}1.49 \\
(60)\end{array}$ & $\begin{array}{l}1 \cdot 37 \\
(54)\end{array}$ & $\begin{array}{l}1 \cdot 63 \\
(61)\end{array}$ & $\begin{array}{l}2 \cdot 00 \\
(55)\end{array}$ & $\begin{array}{l}3 \cdot 48 \\
(34)\end{array}$ \\
\hline 900 & $\begin{array}{l}1 \cdot 10 \\
(34)\end{array}$ & $\begin{array}{l}1 \cdot 19 \\
(36)\end{array}$ & $\begin{array}{l}\mathbf{1 \cdot 0 6} \\
(31)\end{array}$ & $\begin{array}{l}1 \cdot 38 \\
(37)\end{array}$ & $\begin{array}{l}1.49 \\
(33)\end{array}$ & $\begin{array}{l}3 \cdot 04 \\
(13)\end{array}$ \\
\hline
\end{tabular}

Explanation as for Table 1. The experiments are: (1) standard configuration for comparison; (2) as (1), but no mean meridional circulation in the basic state; (3) as (1), but linearization is about a completely motioniess basic state; (4) 'optimally tuned' version (see text), as (1); (5) as (4), but linear model forced with lower part of LMD diabatic heating field only, given by layer $1000-700 \mathrm{mb} ;(6)$ the reverse of $(5)$-i.e. linear model forced with upper part of LMD heating field: $700-0 \mathrm{mb}$.

Thus, the choice of an optimal set of parameters is somewhat subjective. It was decided to favour the fit of the horizontal wind at lowest level, consistent with our interest in airsea coupling. For this purpose, a 30 to $50 \%$ increase in Rayleigh friction together with a $50 \%$ increase in Newtonian cooling worked well and resulted in a correct linear prediction amplitude at most levels. Use of a Newtonian cooling that is constant with height brought some further improvements, however. Thus, the 'optimally tuned' model has the same parametrization for the Rayleigh friction. with a $50 \%$ increase in damping strength, together with a simpler uniform Newtonian cooling, with a 3-day damping time. As seen in Table 2 (experiment 4 ), the agreement is good for the horizontal wind, but the vertical velocity is underestimated at low levels. Our inability to improve the fit simultaneously for $u, v$ and $\omega$ at all levels stresses the limitation of the linear model: there seems to be no substitute for the missing physics, even if acceptable agreement can be found. 
Recent work by Lindzen and Nigam (1987) and Neelin (1988) suggests that the large-scale flow in the tropical boundary layer is basically decoupled from the flow at upper levels, and hence that it may be possible to simulate the tropical surface wind using models of the trade-cumulus layer alone. Thus, it is of interest to examine the sensitivity of the linear model response to the vertical distribution of diabatic heating. Two simulations were performed with the 'tuned' model linearized about the full mean flow. In the first experiment ( 5 in Table 2), the model was forced with the GCM heating in the layer $1000-700 \mathrm{mb}$, i.e. the trade-cumulus layer only. In the second experiment $(6$ in Table 2), the linear model was forced with the GCM heating above $700 \mathrm{mb}$. Table 2 indicates that the skill for the surface wind is indeed little diminished if the forcing is confined to the trade-cumulus layer only, while at $850 \mathrm{mb}$ the contributions of low- and high-level heatings are about equal. Diabatic heating within the trade-cumulus layer is balanced purely by ascent, if horizontal temperature advection and Newtonian cooling are negligible, and this ascent is reflected in the wind in the trade-cumulus layer. Thus the surface wind is relatively insensitive to heating at mid-levels. On the other hand, the omega field in the mid troposphere and the wind at upper levels are little affected if the low-level heating is suppressed.

The simulated horizontal wind fields at $950 \mathrm{mb}$ for the two cases (experiments 5 and 6) are illustrated in Fig. 10. As expected, the flow associated with the trade-cumulus layer heating (Fig. 10(a)) looks rather similar to that for the entire heating (experiment 4 , not shown, and experiment 1, Fig. 8(b)), except that the cross-equatorial flow is stronger. In contrast, the flow associated with mid-tropospheric heating (Fig. 10(b)) is much weaker and more zonal in character with largest magnitudes near the equator; resembling the lower limb of a Walker circulation centred near the dateline. However, this component of the low-level flow is clearly important along the equator over the Pacific. Whilst the LMD diabatic heating in the layer $850-700 \mathrm{mb}$ (not shown) strongly reflects the SPCZ seen at $400 \mathrm{mb}$ (Fig. 6(a)), there is also a narrow zonally-elongated north-south dipole which straddles the equator over the eastern Pacific, a trace of which can be seen below $850 \mathrm{mb}$ (Fig. 6(b)). This heating dipole is confined to within a few degrees of the equator, and produces a thermally-direct meridional circulation spanning
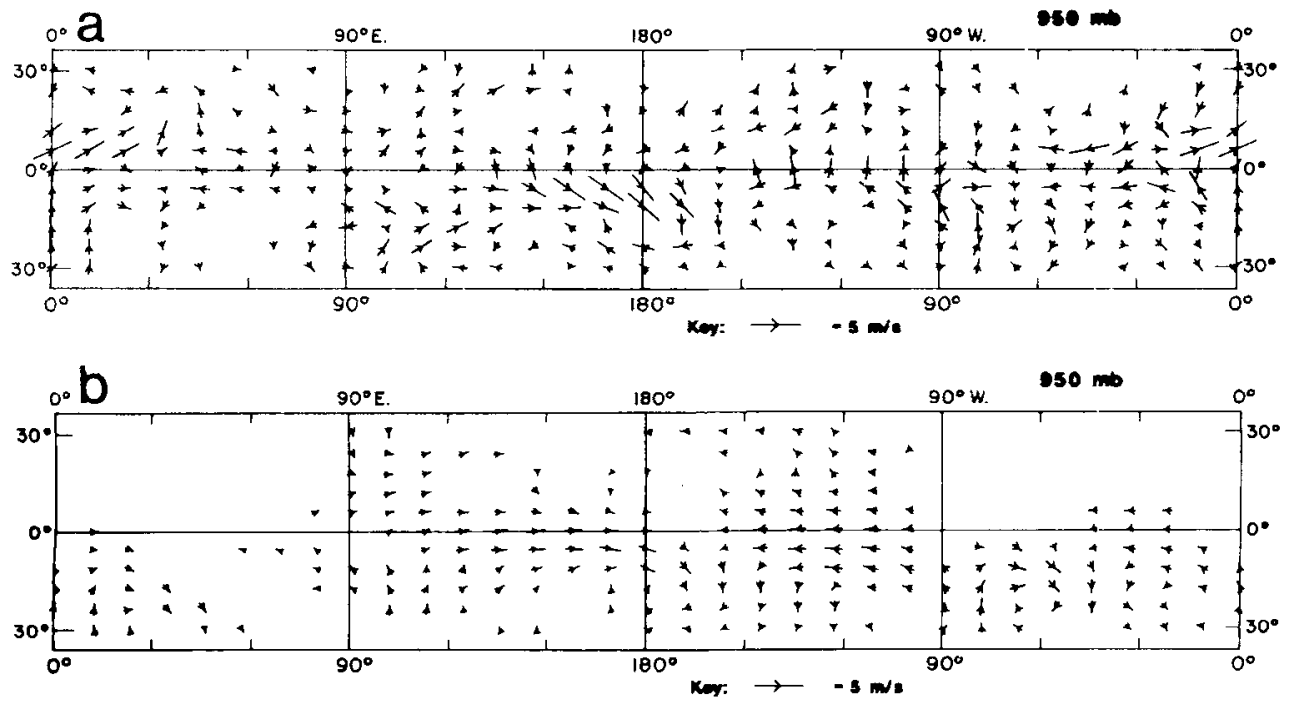

Figure 10. 'Optimally tuned' linear simulation of the LMD horizontal wind at $950 \mathrm{mb}$, when the forcing is restricted to the layers: (a) $1000-700 \mathrm{mb}$; and (b) $700-0 \mathrm{mb}$. 
the equator, whose lower branch corresponds to the strong cross-equatorial flow at $950 \mathrm{mb}$ seen in Fig. 10(a). The LMD diabatic heating field in the layer $850-700 \mathrm{mb}$ is considerably larger than that below $850 \mathrm{mb}$, especially in the region of the SPCZ, suggesting that latent-heat release is important just below $700 \mathrm{mb}$, and that the top of the trade-cumulus layer is rather lower in this case. Consistent with our results, Lindzen and Nigam (1987) suggest from an analysis of the FGGE (northern) winter data, that the trade-cumulus layer may indeed be rather lower than $700 \mathrm{mb}$ in winter, and that the pressure field at low levels then has a component associated with atmospheric motions aloft.

\section{Summary AND CONClusions}

A hypothesis-testing strategy has been used to evaluate how well the Walker circulation in two GCM February tropical climatologies could be reproduced with a thermally forced linear model. We have quantified the performance of the simple model, taking into account the natural variability of the GCM, and investigated its sensitivity to dissipation, the basic flow, and the heating distribution in the vertical.

The main result of this work is that the linear model is consistent with part of the GCM's Walker circulation in both cases at a high level of statistical significance. The significance is largest for the LMD GCM, because it has a larger signal-to-noise ratio with regard to tropical zonal asymmetries than the GISS model. The skill with which the GCM climatologies are reproduced is high for vertical velocity, but limited for horizontal wind. Thus simple linear dynamics explains only a limited part of the zonally asymmetric component of the tropical flow. In the vertical, the skill is consistent with a first baroclinic mode response, reaching a maximum in the middle troposphere for $\omega$, and at low and high levels for $\mathbf{v}$.

For the omega fields, the linear prediction accounts for over $80 \%$ of the GISS $(70 \%$ of the LMD) spatial variance, at mid-levels, reflecting the near-linear balance in the thermodynamic equation in the tropics. At $900 \mathrm{mb}$, the skill is rather low, probably reflecting in part the inadequate resolution of the linear model in the boundary layer, and the differences in the grid-staggering in the vertical. The maximum skill for the horizontal wind in the troposphere occurs at low levels, reaching more than $30 \%$ for the GISS GCM, and more than $40 \%$ for the LMD one. However, although the LMD climatology is best reproduced at $950 \mathrm{mb}$, the GISS simulation scores only a few percent here. This is probably due to the complex vertical structure of the diabatic heating in the boundary layer of the GISS model, which cannot be well represented by the coarseresolution linear model. There is no skill in the mid troposphere because of the small signal-to-noise ratio there.

The sensitivity to the dissipation parametrization in the linear model was investigated using both GCM climatologies as targets, and optimal values were obtained in the LMD case, although the linear simulations are not very sensitive to small changes. It was found that confining the strong dissipation to regions of the critical lines, as suggested by Simmons (1982), did worsen the simulations significantly, underlining the need for high uniform dissipation rates in the tropics in linear models, and validating the formulation of Nigam et al. (1986). The simulation of the LMD wind field deteriorated considerably, especially at upper levels, when terms involving the zonal-mean wind were neglected, illustrating the importance of these terms in the upper-level vorticity balance. The GISS simulation showed less sensitivity. Little sensitivity was shown to terms involving the mean meridional circulation in either simulation, so that the latter need not be represented. In the LMD case it was found that the low-level wind prediction is relatively insensitive to 
the diabatic heating above $700 \mathrm{mb}$. This agrees with recent theoretical work of Lindzen and Nigam (1987) and Neelin (1988). However, whilst low-level forcing accounts for most of the horizontal wind response at $950 \mathrm{mb}$, the cross-equatorial flow over the Pacific is significantly moderated by the Walker circulation forced at middle levels. Thus, a boundary-layer model should not suffice for the prediction of the surface wind for coupled atmosphere-ocean studies.

We have considered the linear model's ability to reproduce the GCM low-level wind in the tropics, as a measure of its suitability for coupling to an ocean model. However, since it is the surface wind stress which actually drives the ocean, it would also be interesting to know to what extent the linear model is capable of reproducing the GCM's surface stress field. Rayleigh friction in the linear model's lowest layer is equivalent to assuming the surface stress to be proportional to the wind (or mass transport) in the lowest layer. However, in a GCM, the surface stress field usually has a quadratic dependence on surface wind velocity, which includes some Ekman turning of the wind in the boundary layer (Hansen et al. 1983). Thus, as demonstrated by Neelin (1988), the linear model's prediction of the GCM's surface stress field might not be quite as good as for the low-level wind.

Encouraging though the simulation of the GCMs is with regard to predicting the zonally asymmetric part of the low-level flow with a simple thermally forced model, only a limited fraction of the spatial variance of the horizontal wind is explained by the linear model in the equatorial band. However, other forcing mechanisms are present in the GCMs, such as orographic and remote forcing. It remains to be seen whether better agreement is obtained when using the linear model to simulate circulation anomalies, which should, in a linear framework, be unaffected by other forcing mechanisms.

\section{ACKNOWLEDGEMENTS}

We are very grateful to B. Lopez de Arias for providing the LMD simulations and some of her unpublished results, and for helping us with the analysis. We also thank $F$. Lott and P. Dandin who performed some of the calculations, and J. Hansen for providing the GISS data. The figures were skilfully drafted by J. Distrophe. The work was supported by a grant from the Commission of the European Communities and by the French National Programme for Climate Research (PNEDC).

Bjerknes, J.

Frankignoul, C. and Molin, A.

Geisler, J. E.

Gill, A.

Hannoschöck, G. and Frankignoul, $\mathrm{C}$.

Hansen, J., Russel, G., Rind, D., Stone, P., Lacis, A., Lebedeff, S., Ruedy, R. and Travis, L.

\section{REFERENCES}

1969

$1988 \mathrm{a}$

$1988 \mathrm{~b}$

1981

1980

1985

1983
Atmospheric teleconnection from the equatorial Pacific. Mon. Weather Rev., 97, 163-172

Response of the GISS general circulation model to a midlatitude sea surface temperature anomaly in the north Pacific. J. Atmos. Sci., 45, 95-108

Analysis of the GISS GCM response to a subtropical sea surface temperature anomaly using a linear model. ibid., 45, 3833-3845

A linear model of the Walker circulation. J. Atmos. Sci, , 38, $1390-1400$

Some simple solutions for heat-induced tropical circulation. Q.J.R. Meteorol. Soc., 106, 447-462

Multivariate statistical analysis of a sea surface temperature anomaly experiment with the GISS general circulation model. J. Atmos. Sci. 42, 1430-1450

Efficient three-dimensional global models for climate studies: Models 1 and 2. Mon. Weather Rev., 111, 609-662 
Hartmann. D. L., Hendon. H. H. and Houze, R. A. Jr

Hoskins, B. J. and Karoly, D.

Kang, I.-S. and Held, I. M.

Latif, M., Biercamp, J. and von Storch, H.

Lim, H. and Chang, C.-P.

Lindzen, R. S. and Kuo, H. L.

Lindzen, R. S. and Nigam, S.

Lopez de Arias, B.

Matsuno, T.

Neelin, J. D.

Nigam, S., Held, I. M. and Lyons. S. W

Phlips, P. J. and Gill, A. E.

Rasmussen, E. M. and

Carpenter, T. E.

Rosenlof, K. H., Stevens, D. E., Anderson, J. R. and Cíesielski, P. E.

Sadourny, R. and Laval, K.

Sardeshmukh, P. D. and Hoskins, B. J.

Simmons, A. J.

Webster, P. J.

Yao, M.-S. and Stone, P. H.

Zebiak, S. E. and Cane, M. A.
1984

Some implications of the mesoscale circulations in tropical cloud clusters for large-scale dynamics and climate. $J$. Atmos. Sci. 41, 113-121

1981

1986

1987

1983

1969

1988

1966

1988

1986

1987

1982

1986

1984

1985

1982

1987

1987

The steady, linear response of a spherical atmosphere to thermal and orographic forcing. ibid., 38, 1179-1196

Linear and nonlinear diagnostic models of stationary eddies in the upper troposphere during northern summer. ibid., 43, 3045-3057

'The response of a coupled ocean-atmosphere general circulation model to wind burst'. Max-Planck-Institüt für Meteorologie, Report No. 6

Dynamics of teleconnections and Walker circulation forced by equatorial heating. J. Atmos. Sci, 40, 1897-1915

Reliable method for numerical integration of a large class of ordinary and partial differential equations. Mon. Weather Rev., 97, 732-734

On the role of sea surface temperature gradients in forcing low level winds and convergence in the tropics. J. Atmos. Sci. 44, 2440-2458

'Response de l'atmosphere tropicale a une anomalie de température oceanique superficielle située dans l'océan Pacifique equatorial'. Thèse de Doctorat de l'Université Paris

Quasi-geostrophic motions in the equatorial area. J. Meteorol. Soc. Jap. . 44, 25-43

A simple model for surface stress and low-level flow in the tropical atmosphere driven by prescribed heating. $Q . J$. R. Meteorol. Soc., 114, 747-770

Linear simulation of the stationary eddies in a GCM, Part 1: The 'no-mountain' model. J. Atmos. Sci., 43, 2944-2961

An analytical model of the heat-induced tropical circulation in the presence of a mean wind. $Q . J . R$. Meteorol. Soc., 113, 213-236

Variations in tropical sea surface temperature and surface wind fields associated with the Southern Oscillation/El Niño. Mon. Weather Rev., 110, 345-384

The Walker circulation with observed zonal winds, a mean Hadley cell, and cumulus friction. J. Atmos. Sci., 43, 449467

January and July performance of the LMD GCM. Pp. 173197 in New perspectives in climate modelling. A. L. Berger and $C$. Nicolis, Eds. Elsevier, Amsterdam

Vorticity balances in the tropics during the 1982-83 El-Niñosouthern Oscillation event. Q.J. R. Meteorol. Soc., 111, $261-278$

The forcing of stationary wave motions by tropical diabatic heating. ibid., 108, 503-534

Response of the tropical atmosphere to local steady forcing. Mon. Weather Rev., 100, 518-541

Development of a two-dimensional zonally averaged statisticaldynamical model. Part I: The parameterisation of moist convection and its role in the general circulation. $J$. Atmos. Sci., 44, 65-82

A model ENSO. Mon. Weather Rev., 115, 2262-2278 